\title{
Implementation Possibilities and Conditionalities of an Internet Platform Designed to Activate Elderly People in the Light of Research Conducted on the Polish Market
}

\author{
K. Łopaciński, R. Kutera, M. Leszczyńska, and W. Gryncewicz
}

\begin{abstract}
The authors deal with the issues of activating elderly people and improving their quality of life in the context of the possibility of increasing their effectiveness through the use of modern ICT solutions. In particular, the paper is focused on checking the possibilities and conditions for successful implementation of the service e-marketplace platform for occupational activation of elderly people in the context of Polish market conditions. The analysis was conducted on the basis of the results of the survey dedicated to elderly people in Poland and supported with in-depth direct interviews. Thanks to it the socio-economical situation of Polish seniors as well as their attitude towards ICTs could be depicted. The concept of the service e-marketplace platform allowing for offering and requesting different kind of occupational activities (incl. part-time work and volunteering) and its key components were presented. That concept has been verified for compliance with the determined implementation conditionalities.
\end{abstract}

Index Terms-Digital competences, needs of elderly people, occupational activation, service e-marketplace platform, voluntary work.

\section{INTRODUCTION}

The change of lifestyle and of the living conditions of the citizens together with the widely understood technological progress (including the medical technology) determine the citizens' higher life expectancy while lowering the fertility rates [1], [2]. This results in the negative birth rate and in the aging of the society. In other words, the share of older people in the population is increasing. What has been observed in recent years is a radical aggravation of this phenomenon. The first consequences of the aforementioned changes are perceptible today; yet, they will be more visible over the coming decades when the processes in question continue in crescendo [3].

Thus, an important question arises as to how the problem of the lack of effectiveness of the current pension systems should be solved in the context of the declining demographic trends. The attempts which are being made to counter this phenomenon, irrespective of its character, are described in the subsequent part of this paper. What should be emphasised at first is the significance of those initiatives whose aim is to stimulate the bottom-up approaches adopted by senior

Manuscript received October 15, 2017; January 17, 2018. The paper is a part of the ActGo-Gate project funded by the AAL Agency awarded on the basis of the agreement number AAL6/1/2015.

The authors are with the Wroclaw University of Economics, Wroclaw, Poland (e-mail: karol.lopacinski@ue.wroc.pl, robert.kutera@ue.wroc.pl, maja.leszczynska@ue.wroc.pl,wieslawa.gryncewicz@ue.wroc.pl). citizens at the pre-retirement and retirement age in order to undertake part-time gainful employment. Some of those initiatives aim at improving the quality of life of the citizens by transferring some of their daily duties to the virtual reality and by automating such tasks fully or partially. In that way senior citizens will have enough time to satisfy high-level needs from Maslow's pyramid, e.g. belongingness, esteem, self-actualization [4].

This line of action is highly important since it is supported by other market trends, such as a dynamic expansion of services, which are understood here as a process of contributing to the creation of value which is specific to a given context [5]. The said value is produced as a result of cooperation between the service providers and their customers within the framework of the same ecosystem, which includes people, organizations, technology, and information resources [6]. Due to the lack of time or competences and due to the growing social and individual well-being [7] the consumers are more willing to use external services in order to create added value. The said value relates not only to the visible effect of the process (the actual work done) but also to the alternative benefits stemming mostly from saving the time, which can be spent on relaxation, self-improvement and social relations.

While taking into account the foregoing remarks, it is worthwhile to search for the possible points of contact between the two phenomena in question and to analyse their prospective application. Within the framework of the international three-year research project the authors address the problem of occupational activation of senior citizens with the application of information and communication technologies (ICT). In order to do so, they have identified and described its economic, social and technological characteristics [8]-[11], and they have suggested a model of implementation of the service e-marketplace platform, which is designed to provide senior citizens with the possibility to offer and order services [12]. They have also presented the aspects of the implementation [13] in the context of the non-functional [14], [15] and functional [16], [17] requirements, which were defined on the basis of the analysis of the target group conducted in Switzerland and Germany during the pilot implementation.

As a result, the service e-marketplace platform has been implemented in three local communities characterized by different territorial features, namely in the countryside, in a small town and in a big city. The implementations helped to verify the preliminary assumptions and to improve the solution by adjusting it to the actual needs and expectations of 
the users.

The main objective of this paper is to identify and analyze the implementation possibilities and conditionalities of the platform in the context of the socioeconomic situation of Polish senior citizens and of their approaches toward ICTs.

\section{THE ANALYSIS OF THE MARKET}

The demographic situation in Poland is undergoing significant changes, what results in the aging of the country's population. In the light of the estimations, the total population of Poland is expected to fall by $3 \%$ between the years 2015 and 2030 and by $10 \%$ between the years 2015 and 2050 . The median age of the population will increase from 39 years of age in 2015 to 45 years of age in 2030 and to 50 years of age in 2050, thus constituting the fifth highest value in the European Union. The population between the ages of 15 to 64 will decrease even more, namely by $11 \%$ between the years 2015 and 2030 and as much as by $28 \%$ between the years 2015 and 2050 [18]. It is envisaged that the demographic burden rate, which means the number of children (aged 0-14) and of elderly people (aged 65 and more) per 100 people aged 15-64, will double: in 2050 it will amount to 105 people (in 2013 it amounted to 58 people). Another measurement applicable to the process of aging of the society, namely the prospective parent care rate, indicates the number of people at the age of 85 and more per 100 people at the age of 50-64. It is estimated that in 2050 it will amount to 38 people as compared to 8 people in the year 2013 [19]. It should also be noted that in Poland elderly people are not very active on the labour market - the employment rate for people aged 50 or more in 2015 was at the level of only $33,4 \%$ (for people aged 50-64 it amounted to 54,6\% and for those at the age of 55-64 it amounted to $46,1 \%$ ) [20]. The increase in professional activity of subsequent generations of Polish citizens at the near-retirement age will mitigate the unfavourable trends. This will be partially caused not only by the application of ad hoc instruments of the labour market (e.g. trainings, internships, grants, socially useful works, intervention works, career guidance, job matching assistance, activation benefits) [21] but also by strategic instruments such as the raising of the statutory retirement age to 67 or elimination of retirement privileges of particular social groups. On the other hand, elderly people belonging to future generations, who will be better educated and familiarized with technologies, will be more willing to prolong their professional lives in order to gain a better quality of life, especially in the context of relatively low retirement pensions. It is estimated that increasing professional activity rates among elderly people will translate into additional half a million people who will be professionally active in the year 2050 [18]. In the light of the decreasing population, this number will be appreciable; however, it will not solve the problem.

Therefore the significance of those initiatives, which aim at the aforementioned bottom-up activation, should be stressed. The said initiatives require the change of long existing habits and routines; thus, they can be regarded as very difficult tasks, whose performance entails a methodological approach toward the problem, diversification of the techniques applied, research methods and project management methodologies.
The initiatives in question are described in the subsequent parts of this paper.

\section{RESEARCH METHODOLOGY}

The research presented in this paper constitutes one of the stages of an international project whose aim is to develop and launch the service e-marketplace platform on the market. The research is conducted in cooperation with the existing organizations and verified on the basis of pilot implementations. The project is carried out both on the technical and business level. The former aims at developing and testing the software which constitutes the basis of the service e-marketplace platform, whereas the latter focuses on creating a business model and a concept of commercialization.

The research within the project are conducted in accordance with the Consortium Research method [22], [23] which assumes the cooperation of scientists and practitioners within the framework of long-term research projects. The method is geared towards producing and verifying scientific artefacts via iterative implementations, where each implementation takes into account previously produced artefacts.

Specifying the implementation possibilities and conditionalities of the service e-marketplace platform on the Polish market required comprehensive original studies of a qualitative and quantitative character.

The first step was to conduct qualitative research in the form of a series of in-depth direct group interviews [24] held during the meetings with Polish senior citizens from senior citizens' centres and Third Age Universities.

What constituted the objective of this research stage was an in-depth analysis of the opinions given by people $50+$ on the activation possibilities offered to senior citizens, on their independence, and improving the quality of life with the application of IT technologies. On the basis of this research a business model of the application of the service e-marketplace platform in the Polish reality has been developed. The most important results and conclusions are presented in a separate paper [25].

The quantitative survey based research constituted the next stage, aimed at assessing the concept of the developed business model of the service e-marketplace platform as well as at determining the level of its usefulness in the Poland. The questionnaire was addressed to people aged 50+ and included 20 questions about living and infrastructure conditions, level of Internet usage and the perception of social and employment activation using ICT. A detailed plan was defined and the study was finally performed between October and December 2016. The survey was conducted among seniors affiliated with senior clubs and Universities of the Third Age. The size of the required (minimal) study sample to reach reliable results was calculate on the basis of the following formula:

$$
N_{\text {min }}=\frac{N_{p}\left(\alpha^{2} * f(1-f)\right)}{N_{p} * e^{2}+\alpha^{2} * f(1-f)}
$$

where:

$N_{\min }-$ minimum study sample size 
$N_{p}$ - the size of the population from which the sample is taken

$\alpha$ - confidence level for results

$f$ - fraction size

$e$ - established maximum measurement error

The population of the sample was 50+. According to the Central Statistical Office, their number in Poland was 13994 300 in 2016 [26]. It was presumed that the confidence level $\alpha$ was set at $95 \%$ (means a $95 \%$ probability that the measurement result is true), the fraction size was at a universal level i.e. 0.5 and the maximum measurement error could equal $5 \%$. On this basis, it was calculated that the required number of respondents in the study was 384 . This requirement was met because the final number of properly completed questionnaires was 406.

\section{RESEARCH RESULTS AND KEY FINDINGS}

It is worthwhile to start the analysis of the survey based research with presenting the structure of the research sample. The research was conducted on a group of 406 individuals aged 50 or more. The most numerous age group was composed of people aged 66-70. They constituted nearly $40 \%$ of the entire research sample. Two second largest age groups were composed of individuals aged 61-65 (20\%) and 71-75 (19\%). There were $12 \%$ of respondents aged more than 75 and $5 \%$ and $4 \%$ of research participants aged 56-60 and 50-55 respectively.

As far as the proportions of respondents by gender and level of education are concerned, there were $76 \%$ of women and $24 \%$ of men. A vast majority of respondents had high or secondary level of education: each of these groups constituted $45 \%$ of the total number of the research participants. There were $9 \%$ of senior citizens with vocational education or secondary-level technical education. Only one in hundred people declared primary-level education.

A vast majority of the respondents, namely more than $84 \%$ of them, receive health pension or retirement pension. Nearly $7 \%$ work under a regular employment contract and 6\% work on a casual basis under a contract of mandate or a contract to perform a specific task. Only $2,5 \%$ of respondents declared that they ran their own company.

As regards housing, nearly $64 \%$ of research participants declared that they lived in flats and $36 \%$ in detached houses. More than half of the respondents (53\%) lived with their spouses or partners, $1,7 \%$ with their siblings and nearly $1 \%$ with their careers. $35,7 \%$ lived alone.

The surveyed people answered a number of questions concerning:

- estimating the degree of use of IT technologies and the level of digital competence,

- identifying the reasons for which some senior citizens are digitally excluded to a different extend or adopt negative attitudes towards ICT,

- specifying the need for services ordered electronically,

- analysing seniors' perception of the prospects of social and occupational activation with the application of ICT.

The research results demonstrate that the senior citizens who participated in the re-search have suitable conditions for using new solutions because $86 \%$ of respondents admitted that they had the access to the Internet and $61 \%$ owned an Internet-enabled mobile phone. It also needs to be said that the degree of use of ICT tools among Polish senior citizens is relatively high. $80 \%$ of respondents use a computer or laptop, and $61 \%$ have a smartphone with internet access. $83 \%$ use the Internet and $54 \%$ of them declared that they did it every day, $31 \%$ several times a week and the lowest frequency of using, namely several times a month or less often, was declared by $14,5 \%$ of respondents. Only $17 \%$ of respondents do not use the Internet at all despite the fact that some of them have access to the Internet at home.

Nearly $58 \%$ of surveyed people use the Internet on their laptop, $47 \%$ use a smartphone, $43 \%$ use for this computer, $19 \%$ - TV, and $18 \%$ - tablet. Only $2 \%$ of respondents use the Internet via the console.

The vast majority, i.e. almost $85 \%$ of respondents who declared their use of the Internet, have their own e-mail account they use. This is the most popular web communication tool among the surveyed people. The results show that seniors communicate over the Internet mainly with relatives and friends. $57 \%$ of respondents answered in this way. Regarding the online contact with institutions, the respondents most commonly use the internet channel to communicate with banks (39\% of responses). On the other hand, they rarely contact the offices ( $25 \%$ of responses) and companies (22\% of responses). Still, it should be recognized that the surveyed seniors showed quite a lot of activity in the field of network communication.

It is also noteworthy that more than half $(51 \%)$ of the respondents declared that they had attended at least one computer course, which indicates that the research participants want to gain knowledge and improve their skills in the field of ICT tools.

This is confirmed by results of the survey that show that people who have taken part in a computer course more often and are more likely use the Internet. $75 \%$ of those who do not use the Internet or use it less than a few times per month are people who have never attended computer training. On the other hand, $65 \%$ of respondents who use the global network every day are people who participated in this kind of training. Furthermore, the impact of training is also evident in aspects related to the perception and acceptance of ICT solutions. Researchers who have completed a computer course in the past compared to those who have never attended such a course have fewer concerns about:

- harmfulness of electronic devices for health,

- negative impact of technology on family life,

- privacy issues arising from the use of the Internet and mobile phones.

There is a positive attitude of the surveyed seniors regarding participation in computer training in the future. More than $65 \%$ of respondents think they would be more adept in using a computer if a professional would teach them. Only $13.1 \%$ of respondents expressed a different opinion.

Due to the above, the level of digital competence of modern seniors in Poland should be assessed as high. The vast majority of them have access to the internet and use its capabilities with not only computers but also mobile devices. Intense use and a more open attitude to information 
technology are visibly influenced by completed computer training. Polish seniors do not negatively evaluate computer technology and its impact on health, family life and privacy. In addition, it is important to emphasize that Polish seniors are highly willing to participate in computer training, where they can improve their skills and learn how to use ICT tools that could be useful in their daily lives. It should be assessed that their self-awareness about the need to acquire and develop digital competence is very high.

By analyzing the results of research in terms of areas of Internet usage by Polish seniors it can be seen that they most often use it to:

- searching for information by the use of search engines,

- reading news from the country and the world,

- searching for addresses and directions on internet maps,

- searching for information related to health and treatment,

- operating online bank account,

- viewing and booking tourist deals,

- using instant messengers.

Unfortunately, many of the capabilities of the global network are still unused by Polish seniors. It is depicted by the results that the elderly very rarely use the Internet to looking for job offers, dealing with official matters, purchasing goods and using dating sites.

This situation also concerns the ordering of various types of services electronically. It turned out that the vast majority, i.e. $74.9 \%$ of respondents, never ordered the service by electronic means. Only 1 respondent per 4 has made such an order. Among the most frequently ordered on-line services are tourist, health and entertainment services. The detailed distribution of the responses can be seen in Fig. 1.

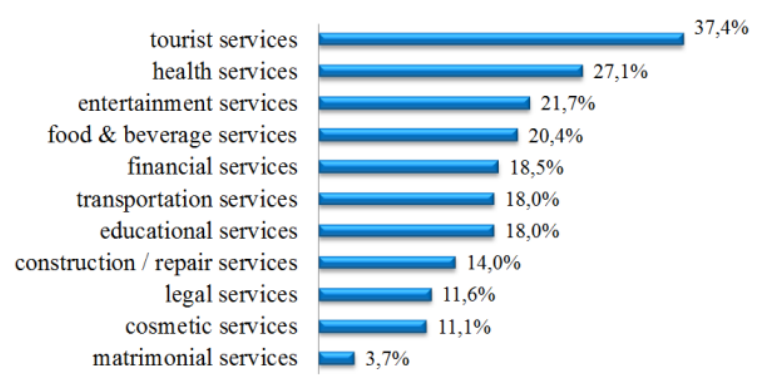

Fig. 1. Types of services ordered by electronic means by respondents.

By analyzing the ways of ordering the aforementioned services, seniors are most likely to prefer email in this area. Nearly half of the respondents, i.e. $48 \%$ of those who order online services, choose this channel. In the second place, the surveyed seniors order services from websites offering services from many industries. $31 \%$ of respondents indicated that answer. The third most popular (30\% response) channel is SMS. By contrast, $23 \%$ of respondents who order services electronically do this through the service providers' websites. Internet communicators (13\% response), industry web portals such as medical, transport, etc. (12\%), online forums $(6 \%)$ and mobile applications $(4 \%)$ are much less frequent used.

In the context of the above, not very optimistic results concerning the scope of ordering electronic services by Polish seniors, it is worth to submit the results of another question. The respondents were asked whether they know that traditional services could be ordered through the Internet. It turned out that over $69 \%$ of responses to this question were negative. This clearly demonstrates that the respondents are poorly aware of the possibility of ordering professional services in various Internet channels and they order these services by traditional means. On the other hand, adequate in-formation policy in this area, as well as the launch of educational and instructional programs, could result in a significant increase in the number of services ordered by electronic means in the 50+ age group. The level of use of ICT tools by Polish seniors and their digital skills is at a level that is sufficient to support e-service platforms. Studies clearly show that the problem of Polish seniors is not the lack of skills in this case, but rather the lack of awareness that traditional services can be ordered via the Internet.

It should be highlight that the research results shows that $34 \%$ of respondents ex-pressed the opinion that they are willing to spend part of their budget on the purchase of external services. This tendency is the higher the frequency of internet usage is. The most willing to order professional services are seniors who are very active Inter-net users. On the other hand, those who did not use the global network showed the least inclination for the mentioned activities. The detailed distribution of responses is shown in Fig. 2.

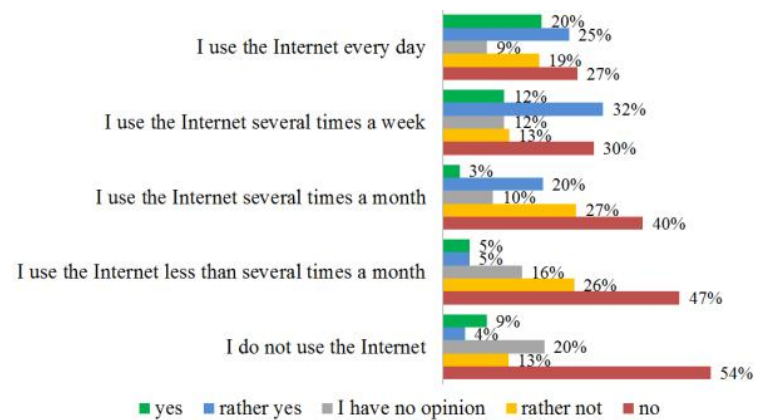

Fig. 2. The willingness of the surveyed seniors to commit part of the budget to purchase services depending on the frequency of the Internet usage.

According to the distribution of responses presented in Fig. 3 , the surveyed seniors showed interest in the opportunities for casual employment, as well as demonstrated their willingness to help others according to their own abilities.

$$
\begin{aligned}
& \text { I am willing to help others according to my skills } \\
& \text { I am interested in the possibility of casual } \\
& \text { employment }
\end{aligned}
$$

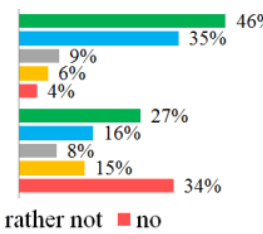

Fig. 3. The willingness of the respondents to help others and interest in the possibility of casual employment.

Research results show that people aged 50+ are still active and interested in casual paid employment as well as voluntary and non-profit projects. People in Poland are retired when they showing great physical and intellectual ability. As a result, seniors have a high level of competence, experience and skills that can be used, for example, as a part-time work. What is more, there is a relationship between mentioned attitudes and the frequency of using the Internet by respondents. Fig. 4 shows that elderly people, who frequently or often use the global network, are much more interested in the possibility of casual work than those who rarely or do not use the Internet. 


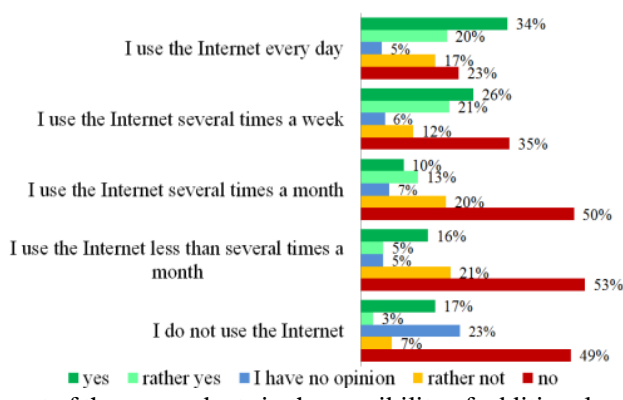

Fig. 4. Interest of the respondents in the possibility of additional employment depending on the intensity of the Internet usage.

Taking into account the tendency of the respondents to help others not necessarily in the form of paid work, the results of the research are even more optimistic. As shown in Fig. 3, presenting the results for the whole study sample, the vast majority of the respondents $(81 \%)$ declared their willingness to help other people according to their own skills. However, by analyzing the results in sections of Internet user groups, it is clear that people who more often use the global network are more likely to help others. It is shown in Fig. 5. It is also worth mentioning that $87 \%$ of respondents who have their own email inbox declared a willingness to such help.

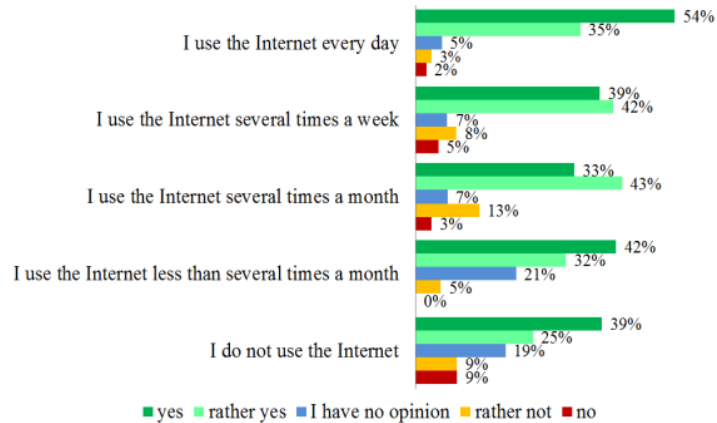

Fig. 5. The willingness of the respondents to help others according to their skills, depending on the intensity of the Internet usage.

In connection with the above results, it can be argued that there is considerable potential for the development of online platforms, which have the capacity to give people aged 50+ the opportunity to earn extra income, as well as to provide various kinds of free help in communities such as local, neighborhood, etc. In order to fully utilize the identified potential of the research group, it is essential to create appropriate conditions for seniors to use, offer and order various kinds of services via Internet. This includes both technical and substantive trainings that raise awareness about how to use the Internet to order and offer traditional services.

\section{SERVICE E-MARKETPLACE PlatForm FOR OCCUPATIONAL ACTIVATION OF ELDERLY PEOPLE AS A RESPONSE TO MARKET DEMAND}

The presented results of the research indicate that there exists a group of elderly people who are willing to use ICT to satisfy their daily consumption needs and to actively search for job opportunities. Therefore, it is appropriate to provide elderly people with a tool which will make these tasks simpler and less time consuming. On the basis of the partners' experiences (social organizations from Germany and Switzerland) and of the trial implementation and testing in different territorial conditions, the concept of the service e-marketplace platform was born. After a short presentation, it will be verified in terms of the implementation possibilities and conditionalities in the light of the quantitative research results. The high-level architecture of the solution is presented in Fig. 6.

The architecture of the ActGo-Gate platform involves 4 key components (Fig. 6):

- Gate Application (AGG),

- Appointment Coordination System (ACS),

- Recruiting Service System (RSS),

- User Management and Identity System (UMIS).

Gate Application (AGG) constitutes a point of contact for all the user groups. It determines the appearance and behaviour of the responsive interfaces dedicated to end users, service providers and employers. Within its framework, the activities of particular users and the transactions executed via all the components of the platform are synchronized. AGG makes its Application Programming Interface (API) available and it uses the client's APIs in order to ensure full synchronicity of data and to provide the access to all the functions of the system. As far as the functional dimension is concerned, the most important task is to provide a tool for searching through the offers and for the management of the user's own ads with the application of navigation paths simplified to a maximum and with the clear, readable interface, which is adjusted to the perception of elderly people.

Clients (ACS and RSS) are the systems constituting autonomous internet services, which deal with specific forms of services and which provide necessary functionalities such as the appointment coordination (in the case of ACS) or recruitment (in the case of RSS). As mentioned above, they have their own APIs, which provide the current data and functionalities required by AGG. Clients have inbuilt email notification (and, additionally, text message notification in the case of ACS), which, in both cases, was extended by sending notifications to AGG. In particular, Clients provide the functional modules of the platform with functionalities.

Serve the Community Module is provided by ACS and offers the IT support for the mutual exchange of services performed by the citizens for the citizens, including the barter trade of services. It also supports service providers in the process of matchmaking consumers with service performers due to the partial automation of tasks, in particular autodispatching of appointments. The intermediary, who has their own Personal Consumer Address Book, orders the services on behalf of other users.

Flexible Occupation Module is provided by ACS too and allows the services to be provided by elderly people on a commercial basis in a form of a part-time employment. The module facilitates finding people who need help through browsing demands, which can be defined as descriptions of the character of the assistance needed.

The response to the demand generates another appointment, which can be managed according to the planned process of the demand-driven appointment coordination. The support in the matchmaking provided by the intermediary is available because of the possibility of acting to the benefit of other users, i.e. in the field of order placement and appointment coordination. 


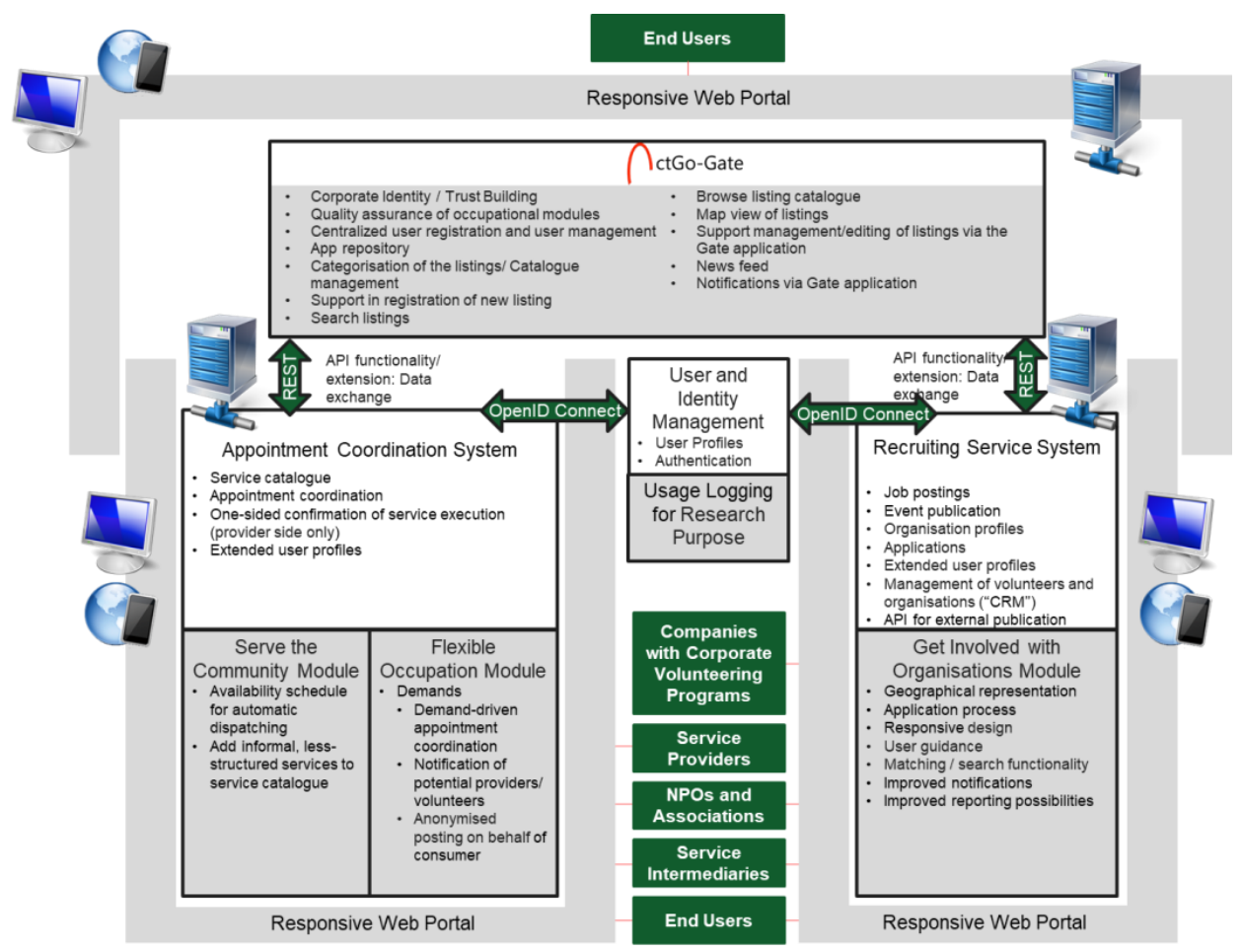

Fig. 6. High-level architecture of service e-marketplace platform for occupational activation of elderly people.

Get Involved with Organizations Module is provided by RSS. It enables to offer services on a voluntary basis. Volunteers can apply to given volunteering projects and the system supports the organization which carries on a given project by conducting the recruitment process and by selecting the most adequate candidates. The system also provides the volunteers with technological and factual support in the field of creating their CVs and it actively supports the process of selecting offers suitable for a given volunteer.

The User Management and Identity System (UMIS) provides ICT tools which facilitate users registration, collecting and processing their data, and user authentication, i.e. providing information on the identity of the users. The latter function is performed due to the application of the OpenID Connect authentication protocol. What constitutes an unquestionable advantage of this technology is a considerable degree of separation of the user data and of the processes related to the management thereof from the other IT systems, what results in the data security improvement. Furthermore, because of such a solution, the entire platform is very interoperable and therefore it is easily extendable by new clients, whose task is to provide complementary services to the platform's current offer.

The system which is designed in such a way allows to support senior citizens in their search for additional employment and for the ways of improvement of their quality of life by offering them the access to the services offered by other professional or private providers. It provides a range of tools which make basic activities friendly for the users.

In the light of the conclusions drawn from the analysis of the research results, what can be identified at first sight is a set of conditionalities which fulfilment may bring the platform closer to its desired objective. The set includes in particular:

- providing senior citizens with a safe environment in which they will carry out their transactions via the ICT platform and store their personal and transactional data,

- providing the continuing access (in person or by phone) to technical and factual support for users,

- activating senior citizens within the existing structures like senior citizens' centres, Third Age Universities,

- using senior citizens' natural need to self-organize and provide mutual assistance,

- enabling senior citizens to offer their services in the form of casual labour,

- enabling organizations trusted by senior citizens (senior citizens' centres, Third Age Universities) and senior citizens themselves to verify the providers of services through opinion systems where customers evaluate the performance of the service.

As far as the first conditionality is concerned, it should be noted that the platform uses secure protocols of the Internet communication and it applies the secure OpenID Connect authentication protocol. The server with user data is separated and properly protected against the possible breaches of security. Thus, from a technical point of view, the application is well adapted to the expectations of the target group. What is very important in this area is communicating these facts to the users in an understandable way and enhancing their awareness in terms of safe techniques of using the application. To this end, introductory trainings for the target group are needed. It is also useful to provide access to the infrastructure (e.g. computers in the intermediaries' offices), which should be properly protected and operated under supervision. There are also plans to implement external systems of payment for services with high standards in safety and reliability among the users. It is also worthwhile to attempt to win the patronage of and certification from the most accomplished social and technological organizations (also from those operating in the field of security of systems). 
Another aspect is providing the continuing access to technical and factual support. What is necessary apart from the aforementioned computer station with the access to the on-site support is the helpdesk, which will facilitate a remote contact by phone or e-mail and current problem solving for those who use the application remotely. It is the intermediary's duty to provide such solutions together with the proper hardware and software infrastructure and human resources.

Senior citizens may be activated with the application of the existing structures via the usage of the structures referred to in the application as "neighborhood". They have their own information pages, news and dedicated catalogues of services just for the members of this neighborhood. Elderly people will be more willing to use the services provided by others if they are offered by people from their vicinity, who belong to the same organization, such as a local senior citizens' centre. Therefore, neighborhoods can be very useful in terms of the natural need to self-organize and to support others, especially those who are close to them.

Elderly people expect that they will be able to work on a casual basis and the application provides them with the possibility to be employed in this way due to all the three modules, but particularly due to the appointment coordination process supported by ACS. The process facilitates negotiating the dates with the usage of any terminal equipment and via the application, notification, email, or text message. The users can also plan their slots of availability. Thus, the system will not offer them works which need to be done on the dates different than the indicated ones. Owing to this, it is possible to plan the day in such a way as to have enough time for the daily duties and for the casual labour.

The last condition which needs to be fulfilled is providing the possibility to verify the services and service providers. Today, the system provides a unilateral confirmation of the service performance; however the introduction of a bilateral verification is intended so that both parties could confirm the quality of the service and the fact that it was performed. What also seems important is the implementation of direct assessment tools which will enable consumers to evaluate the performance of services. However, currently the platform does not offer such a solution, even though it is desired not only by the Polish users. Therefore, the implementation of those tools constitutes one of the priorities in terms of the future development of the platform.

\section{Closing Remarks}

The improving socio-economical situation of Polish seniors as well as their increasingly positive attitude towards ICTs cause that the perspective of ICT-based occupational activation emerges. The results of the conducted survey show that seniors in Poland are beginning to notice the potential benefits of use the technology in their day-to-day operations. In parallel they would like to stay active and be engaged into the social and cultural life. They are willing to help others for free as a volunteer or earn additional money for the short-term occupational activity.

That is why the platform for integrating seniors who need help and look for help and making them connected with voluntary organizations and professional service providers could be a very useful solution. In compliance with service economy development trends [27], [28] such a platform can shorten the time needed for looking for occupational opportunities and requesting them as well as provide a wide range of different kinds of offers at one place in the unified and therefore easily comparable forms.

The results of the analysis of implementation possibilities and conditionalities on the Polish market show that this market is rather at the early stage of development and there are still some limitations resulting from the lack of sufficient infrastructure and competences. However there is a perspective that a significant group of digitally-aware and digitally-capable people who, after a short training, can utilize the special features of the service e-marketplace platform.

\section{REFERENCES}

[1] H. R. Moody, Abundance of Life. Human Development Policies for an Aging Society, Columbia University Press, 2013.

[2] J. W. Rowe and R. L. Kahn, "Successful aging 2.0. conceptual expansions for the 21st Century," J Gerontol B Psychol Sci Soc Sci, vol. 70, pp. 593-596, 2015.

[3] M. Kiełkowska, "Wprowadzenie," in Rynek Pracy Wobec Zmian Demograficznych, M. Kiełkowska, Ed. Warszawa: Instytut Obywatelski, 2013, p. 5.

[4] M. Amani and M. J. Shabahang, "The relationship of self-efficacy and money attitudes with mental health. Mediation through Maslow's hierarchy of needs," International Journal of Culture and Mental Health, vol. 56, pp. 1-10, 2017.

[5] S. L. Vargo and R. F. Lusch, "Institutions and axioms. An extension and update of service-dominant logic," J. of the Acad. Mark. Sci., vol. 44, pp. 5-23, 2016.

[6] P. P. Maglio, S. K. Kwan, and J. Spohrer, "Commentary - Toward a research agenda for human-centered service system innovation," Service Science, vol. 7, pp. 1-10, 2015.

[7] A. Dąbrowska, "Postawy polskich konsumentów - od konsumpcjonizmu do zrównoważonej konsumpcji," Handel Wewnętrzny, pp. 88-100, 2015.

[8] W. Gryncewicz, R. Kutera, M. Leszczyńska and B. Butryn, "Cyfrowe kompetencje osób starszych w dobie rozwoju społeczeństwa informacyjnego," in Wiedza w przedsiębiorczości - aspekty technologiczne, organizacyjne i społeczne, I. Pawełoszek, C. Stępniak, Eds. Wydawnictwo Wydziału Zarządzania Politechniki Częstochowskiej, 2015.

[9] Ł. Łysik, R. Kutera, and P. Machura, "Social collaboration solutions as a catalyst of consumer trust in service management platforms - a research study," in Proc. 18th International Conference in Business Information Systems, 2015, pp. 220-232, vol. 208.

[10] M. Leszczyńska, R. Kutera, B. Butryn, and W. Gryncewicz, "Wpływ makrootoczenia na aktywizację cyfrową seniorów w Polsce," Przegląd Organizacji, pp. 65-71, 2016.

[11] B. Butryn, W. Gryncewicz, R. Kutera, and M. Leszczynska, "The application of PEST analysis to the creation of the profile of na IT product designed to activate and support senior citizens in Poland," in Proc. the Fourth International Conference on Telecommunications and Remote Sensing, SCITEPRESS, 2015, pp. 109-115.

[12] R. Kutera, W. Gryncewicz, M. Leszczynska, and B. Butryn, "The model of delivering an IT product designed to activate and support senior citizens in Poland," Annals of Computer Science and Information Systems, pp. 195-202, vol. 9, 2016.

[13] R. Kutera and W. Gryncewicz, "Web Oriented Architectural Styles for Integrating Service E-marketplace Systems," in Proc. the Seventh International Symposium on Business Modeling and Software Design, 2017.

[14] R. Kutera and W. Gryncewicz, "Single sign on as an effective way of managing user identity in distributed web systems. The ActGo-Gate project case study," Informatyka Ekonomiczna, vol. 40, pp. 25-43, 2016.

[15] L. Maciaszek, W. Gryncewicz, and R. Kutera, "Integrated service e-marketplace for independent and assisted living - business and software engineering challenges," Lecture Notes in Business Information Processing in Business Modelling and Software Design, pp. 221-231, vol. 208, 2016. 
[16] A. Rot, R. Kutera, and W. Gryncewicz, "Design and assessment of user interface optimized for elderly people. A case study of actgo-gate platform," in Proc. the 3rd International Conference on Information and Communication Technologies for Ageing Well and e-Health: SCITEPRESS - Science and Technology Publications, 2017, pp. 157-163.

[17] R. Kutera, T. Skalniak, and W. Gryncewicz, "Towards an Architecture of Electronic Service Market System - requirements analysis and evaluation," Annals of Computer Science and Information Systems, 2017.

[18] A. Kiełczewska and P. Lewandowski, "Starzenie się ludności a podaż pracy w Polsce w horyzoncie roku 2050," in Starzenie się ludności, rynek pracy i finanse publiczne $w$ Polsce, P. Lewandowski, J. Rutkowski, Eds. IBS, 2017, p. 11.

[19] Central Statistical Office, Prognoza ludności na lata 2014-2050, Warsaw, 2014.

[20] Ministry of of Family, Labour and Social Policy, Rynek pracy w Polsce w 2015 roku, Warsaw, 2016.

[21] M. Danecka, "Bezrobotni-niewykorzystane zasoby rynku pracy wobec problemów demograficznych," in Rynek Pracy Wobec Zmian Demograficznych, M. Kiełkowska Ed. Warszawa: Instytut Obywatelski, 2013, p. 25.

[22] H. Oesterle and B. Otto, "Consortium research," Business \& Information Systems Engineering, vol. 2, pp. 283-293, 2010.

[23] B. Otto and H. Oesterle, "Relevance through consortium research? Findings from an expert interview study," in Global Perspectives on Design Science Research, D. Hutchison et al. Eds., Berlin: Springer, 2010, pp. 16-30.

[24] S. Brinkmann and S. Kvale, InterViews. Learning the Craft of Qualitative Research Interviewing, Los Angeles, Calif.: Sage, 2015.

[25] R. Kutera, K. Łopaciński, M. Leszczyńska, and W. Gryncewicz, "Business model for occupational activation of elderly people via the service e-marketplace platform - Research study of polish market," in MCCSIS 2017 Proc. the IADIS Multi Conference on Computer Science and Information Systems, Lisbon: IADIS Press, 2017.

[26] Central Statistical Office, Demographic Yearbook of Poland, Warsaw, 2016.

[27] Z. Zhou. (2016). The basic features of service economy development trend. Springer Singapore. [Online]. Available: http://link.springer.com/chapter/10.1007/978-981-287-901-1_6/fullte xt.html.

[28] J. Gallouj, K. M. Weber, M. Stare, and L. Rubalcaba, "The futures of the service economy in Europe. A foresight analysis," Technological Forecasting and Social Change, vol. 94, pp. 80-96, 2015.

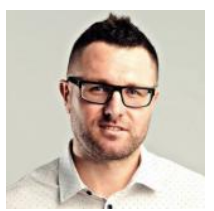

Karol Lopaciński was born in Wroclaw, Poland on June 27, 1980.

He got the master's degree in economy from the Faculty of National Economy, Wroclaw University of Economics, Poland in 2004; Ph.D. degree in economy, at the Faculty of Management and Informatics at Wroclaw University of Economics, Poland in 2013.

Currently he is an adjunct in the Department of Information Systems at the Wroclaw University of Economics, where he conducts research and teaches students.

Currently he is researcher in the project Active Retiree and Golden Workers Gate under the Ambient Assisted Living EU program. And he is the co-founder of Sciencemeets.biz think tank.

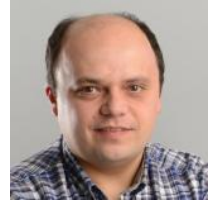

Robert Kutera was born in Gora, Poland on May 12 1982.

He got the master's degree in economy from the Faculty of Management and Informatics at Wroclaw University of Economics, Poland in 2006; He completed full-time doctoral studies at the Faculty of Management, Computer Science and Finance at the Wroclaw University of Economics, Poland in 2010.

$\mathrm{He}$ is currently holding a position of business analyst in an international research project entitled "Active Retiree and Golden Workers Gate" under the Ambient Assisted Living EU program) at Wroclaw University of Economics in Wroclaw (Poland); Co-founder of Sciencemeets.biz think tank. Since 2007 he has given lectures and classes at the Wroclaw University of Economics and the University of Business in Wroclaw;

Mr Kutera is the author /co-author of 50 scientific articles and speaker at many scientific conferences, both national and international in the area of business informatics; the beneficiary and participant in 12 research projects in the area of business communications, e-business and social media financed from EU funds and grants of Polish Ministry of Science and Higher Education.

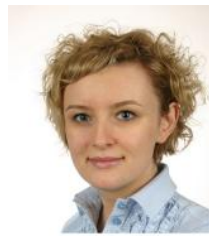

Maja Leszczyńska was born in Czestochowa, Poland on September 26, 1980 .

She got the bachelor's degree in finance from the Faculty of Finance at Cracow University of Economics, Poland in 2003; master's degree in management from the Faculty of Management at Czestochowa University of Technology, Poland in 2004; Ph.D. degree in economy from the Faculty of Management and Informatics at Wroclaw University of Economics, Poland in 2013.

She is currently holding a position of assistant professor at Wroclaw University of Economics, Poland. At the University she is the head of postgraduate studies Cyber Security Management (since 2013) and head of the ICT Accelerator research center (since 2016). She is also an economic expert reviewing applications for financing of $R \& D$ projects which are filed under the Operational Programme Intelligent Development in the National Centre for Research and Development (since 2017).

Now she is researcher in the project Active Retiree and Golden Workers Gate, November 2014 - November 2017.

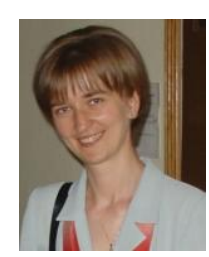

Wiesława Gryncewicz was born in Kluczbork, Poland on January 9, 1974

She got the $\mathrm{PhD}$ in economic sciences in economics in 2007; master's degree of economics from Wroclaw University of Economics, Faculty of Management and Computer Science in 1998.

She is an assistant professor from the Department of Information Systems at Wroclaw University of Economics, Poland; she is a head of an international project Active Retiree and Golden Workers Gate from 2014 to 2017.

Dr. Gryncewicz is the author or co-authored over 60 articles, she participated in several national and international scientific conferences, during which she delivered papers. Dr. Gryncewicz is a member of Naukowe Towarzystwo Informatyki Ekonomicznej - NTIE and a secretary of Wrocławskie Koło NTIE. She also serves in Program Committee of International Conference on Enterprises Information Systems (ICEIS). 